\title{
PENGARUH SISTEM OLAH TANAH DAN PEMBERIAN HERBISIDA TERHADAP ALIRAN PERMUKAAN DAN EROSI PADA PERTANAMAN JAGUNG (Zea mays L.) MUSIM TANAM KE-3
}

\author{
Maksum Amin Jauhari, Irwan Sukri Banuwa, Afandi dan Muhajir Utomo \\ Jurusan Agroteknologi, Fakultas Pertanian, Universitas Lampung \\ Jl. Prof. Dr. Soemantri Brojonegoro, No. 1 Bandar Lampung 35145 \\ Email :jauhari378@gmail.com
}

\begin{abstract}
ABSTRAK
Penelitian bertujuan untuk mengetahui pengaruh (1) sistem olah tanah terhadap aliran permukaan dan erosi yang terjadi di lahan pertanaman jagung; (2) pemberian herbisida terhadap aliran permukaan dan erosi yang terjadi di lahan pertanaman jagung; (3) interaksi antara sistem olah tanah dan pemberian herbisida terhadap aliran permukaan dan erosi yang terjadi di lahan pertanaman jagung. Penelitian dilaksanakan pada bulan Oktober 2016 sampai bulan Februari 2017 di Laboratorium Lapang Terpadu dan Laboratorium Ilmu Tanah, Fakultas Pertanian, Universitas Lampung. Rancangan yang digunakan yaitu rancangan faktorial dalam Rancangan Acak Kelompok Lengkap (RAKL) dengan dua faktor perlakuan. Faktor yang pertama adalah sistem olah tanah dan faktor kedua adalah pemberian herbisida, perlakuan diulang sebanyak empat kali. Hasil penelitian menunjukkan bahwa (1) aliran permukaan, erosi, tinggi tanaman, bobot basah gulma, bobot basah brangkasan tanaman dan produksi tanaman jagung pada olah tanah minimum tidak berbeda dibandingkan dengan olah tanah penuh; (2) aliran permukaan dan erosi pada perlakuan pemberian herbisida tidak berbeda dibandingkan dengan tanpa pemberian herbisida, tetapi pemberian herbisida nyata lebih baik pada komponen tinggi tanaman, bobot basah gulma, bobot basah brangkasan dan produksi tanaman jagung; (3) Tidak ada interaksi yang terjadi antara perlakuan sistem olah tanah dan herbisida terhadap aliran permukan dan erosi, tinggi tanaman, bobot basah gulma, bobot basah brangkasan tanaman dan produksi tanaman jagung.
\end{abstract}

Kata kunci : aliran permukaan, erosi, herbisida, olah tanah

\section{PENDAHULUAN}

Jagung (Zea mays L.) merupakan salah satu tanaman pangan dunia yang terpenting, selain gandum dan padi. Di Indonesia jagung merupakan makanan pokok kedua setelah beras yang dikonsumsi penduduk sebagai sumber karbohidrat. Menurut Roesmarkam (2002), kebutuhan akan jagung di Indonesia mengalami peningkatan yaitu kebutuhan jagung sebagai sumber karbohidrat manusia meningkat sekitar $5,16 \%$ per tahun, kebutuhan jagung juga meningkat sekitar $10,87 \%$ per tahun sebagai sumber bahan industri serta sebagai bahan pakan ternak. Dengan demikian perlu dilakukan peningkatan produksi jagung dengan penambahan produktivitas lahan dengan cara menyediakan media tanam yang baik.Langkah yang perlu dilakukan untuk menyediakan media tanam yang baik adalah pengolahan tanah. Tujuan dari olah tanah yaitu untuk menggemburkan tanah, mencampurkan serasah sisa tanaman dengan tanah, dan menciptakan kegemburan tanah sebagai tempat tumbuh dan berkembangnya akar dengan baik (Gill and Vanden Berg, 1967).
Pengolahan tanah modern dapat dibagi menjadi dua, yaitu pengolahan tanah konvensional dan pengolahan tanah konservasi (Gajri, dkk., 2002). Pengolahan tanah konvensional dikenal juga dengan istilah Olah Tanah Intensif (OTI). Pada pengolahan tanah intensif, tanah diolah beberapa kali baik menggunakan alat tradisional seperti cangkul maupun dengan bajak singkal. Pada sistem OTI, permukaan tanah dibersihkan dari rerumputan dan mulsa, serta lapisan olah tanah dibuat menjadi gembur agar perakaran tanaman dapat berkembang dengan baik (Utomo, 2012). Pengolah tanah konservasi adalah penyiapan lahan yang menyisakan sisa tanaman di atas permukaan tanah sebagai mulsa dengan tujuan untuk mengurangi erosi dan penguapan air dari permukaan tanah. Utomo (1995) mendefinisikan olah tanah konservasi sebagai suatu cara pengolahan tanah yang bertujuan untuk menyiapkan lahan agar tanaman dapat tumbuh dan berproduksi optimum, namum tetap memperhatikan aspek konservasi tanah dan air. Salah satu pengolahan tanah konservasi adalah pengolahan tanah minimum, yaitu pengolahan tanah yang dilakukan secara terbatas atau seperlunya 
tanpa melakukan pengolahan tanah pada seluruh areal lahan (Lembar Informasi Pertanian, 1994).

Erosi merupakan perpindahan suatu material tanah yang dibantu oleh media air dan angin dari suatu tempet ke tempat lainnya (Arsyad, 2010). Erosi menyebabkan hilangnya lapisan atas permukaan tanah yang kaya unsur hara dan berkurangnya kemampuan tanah menyerap dan menahan air (Banuwa, 2013).

Vegetasi merupakan tanaman yang menutupi permukaan tanah baik itu tanaman budidaya maupun tanaman pengganggu (gulma). Vegetasi ini memiliki peran dalam menekan dan mencegah aliran permukan serta erosi.

Hebisida merupakan senyawa atau material yang disebarkan pada lahan pertanian untuk menekan atau memberantas tumbuhan yang menyebabkan penurunan hasil (gulma) (Sembodo, 2010). Penggunaan herbisida dengan bahan aktif glyfosfat sangat efektif dan efisien dari segi waktu sebab herbisida ini bersifat sistemik dalam pengendalian gulma.

Berdasarkan latar belakang di atas disusun perumusan masalah sebagai (1) apakah sistem olah tanah berpengaruh terhadap aliran permukaan dan erosi yang terjadi di lahan pertanaman jagung. (2) apakah pemberian herbisida berpengaruh terhadap aliran permukaan dan erosi yang terjadi di lahan pertanaman jagung. (3) apakah terdapat interaksi antara sistem olah tanah dan pemberian herbisida tyerhadap aliran permukaan dan erosi yang terjadi di lahan pertanaman jagung.

\section{METODE PENELITIAN}

Penelitian ini dilaksanakan di Laboratorium Lapang Terpadu Fakultas Pertanian Universitas Lampung dan Laboratorium Ilmu Tanah Fakultas Pertanian Universitas Lampung.Penelitian Ini dilakukan pada bulan Oktober 2016 sampai Februari 2017. Bahan yang akan digunakan pada penelitian ini adalah tanah, tanaman jagung sebagai vegetasi, pupuk urea, pupuk SP36, pupuk KCl, kompos dan herbisida glyfosat 2,4 D. Alat yang digunakan pada penelitian ini adalah petak erosi, timbangan, oven, gelas ukur, cawan, sarung tangan, penjepit, sendok, ember, seng, ajir, cangkul, saringan, drum penampung, alat hitung, alat ukur dan alat tulis.

Penelitian petak erosi ini menggunakan Rancangan Faktorial 2x2, dengan 4 kali ulangan. Faktor pertama meliputi Sistem Olah Tanah, yakni M (pengolahan tanah minimum) dan $\mathrm{F}$ (pengolahan tanah penuh), dan faktor kedua meliputi Herbisida yakni $\mathrm{H} 1$ (pemberian herbisida), H0 ( tanpa pemberian herbisida). Sehingga didapat 16 perlakuan.Percobaan tersebut disusun dalam Rancangan Acak Kelompok Lengkap (RAKL).Data yang diperoleh kemudian diuji homogenitas ragamnya dengan uji Bartlett, bila asumsi terpenuhi data diuji kemenambahannya dengan uji Tukey.Bila kedua asumsi terpenuhi data dianalisis ragam dan dilakukan pemisahan nilai tengah dengan uji (BNT) pada taraf $5 \%$.

Pengamatan dan pengukuran dilakukan selama masa vegetatif tanaman jagung sampai panen yaitu pengukuran curah hujan, pengukuran aliran permukaan, pengukuran erosi, tinggi tanaman, pengukuran produksi, berat basah gulma, dan berat basah berangkasan tanaman jagung.

\section{HASIL DAN PEMBAHASAN}

Hasil penelitian (Tabel 1 ) menunjukkan bahwa perlakuan sistem olah tanah tidak nyata mempengaruhi seluruh variabel yang diamati. Perlakuan herbisida nyata mempengaruhi tinggi tanaman, bobot basah gulma, bobot basah brangkasan tanaman jagung dan produksi jagung namun tidak mempengaruhi aliran permukaan, erosi dan tanaman jagung. Demikian pula interaksi perlakuan

Tabel 1. Hasil analisis ragam pengaruh sistem olah tanah dan herbisida terhadap aliran permukaan, erosi, tinggi tanaman, bobot basah gulma, bobot basah brangkasan tanaman dan produksi.

\begin{tabular}{clccc}
\hline \multirow{2}{*}{ No } & \multicolumn{1}{c}{ Variabel } & \multicolumn{3}{c}{ Perlakuan } \\
\cline { 3 - 5 } & & OT & H & OtxH \\
\hline 1 & Aliran permukaan (mm) per musim tanam & tn & tn & tn \\
2 & Erosi (kg/ha) per musim tanam & tn & tn & tn \\
3 & Tinggi tanaman (cm) & tn & $*$ & tn \\
4 & Bobot basah gulma (ton/ha) & tn & $*$ & tn \\
5 & Bobot basah brangkasan tanaman jagung (ton/ha) & tn & $* *$ & tn \\
6 & Produksi (ton/ha) & tn & $*$ & tn \\
\hline
\end{tabular}

Keterangan: OT = Olah tanah; $\mathrm{H}=$ Herbisida; OTxH = Interaksi olah tanah dan herbisida; $\mathrm{tn}=$ Tidak berbeda nyata pada taraf $=0,05 ; *$ dan $* *=$ masing-masing berbeda nyata dan sangat nyata pada taraf $=0,05$ dan 0,01 . 
sistem olah tanah danpemberian herbisida tidak nyata mempengaruhi semua variabel yang diamati.

\section{Pengaruh Sistem Olah Tanah dan Herbisida terhadap Aliran Permukaan}

Hasil penelitian menunjukkan bahwa perlakuan olah tanah dan herbisida serta interaksi keduanya tidak berpengaruh nyata terhadap aliran permukaan (Tabel 2).Hal tersebut dikarenakan curah hujan yang rendah selama periode penelitian.Hasil penelitian ini tidak sejalan dengan Suwardjo (1981) yang menyatakan bahwa perlakuan tanpa pengolahan tanah dengan pemberian mulsa nyata menekan aliran permukaan dibandingkan dengan perlakuan pengolahan tanah biasa tanpa pemberian mulsa. Hal ini disebabkan curah hujan yang terjadi pada penelitian Suwardjo sebesar $1484 \mathrm{~mm} /$ musim tanam, sedangkan total curah hujan yang terjadi selama penelitian ini hanya sebesar $160,11 \mathrm{~mm} /$ musim tanam. Dengan penyebaran hujan yang tidak kontinyu total curah hujan yang terjadi tersebut sangat kecil menimbulkan aliran permukaan yaitu sebesar $13,11 \%$ pada perlakuan pemberian herbisida, perlakuan olah tanah penuh sebesar $11,87 \%$, perlakuan olah tanah minimum sebesar $10,34 \%$ dan perlakuan tanpa pemberian herbisida menimbulkan aliran permukaan sebesar 9,10\%. Jika curah hujan tinggi, maka menurut ( Troeh dkk, 1980 dalam Banuwa, 2013) pada tanah yang tidak permeable, lereng curam dan kondisi vegetasi yang buruk, dapat menimbulkan aliran permukaan yang besarnya dapat mencapai $75 \%$ dari hujan.

Berdasarkan penerapan di lapangan dengan perlakuan olah tanah penuh yaitu tanah diolah secara penuh dengan pencangkulan beberapa kali sehingga tanah menjadi gembur kemudian sisa tanaman dan gulma tidak dimanfaatkan sebagai penutup.Perlakuan olah tanah minimum tanah hanya diolah seperlunya saja dengan pemberian mulsa sebagai penutup tanah. Sehingga aliran permukan yang terjadi pada perlakuan olah tanah minimum seyogyanya lebih kecil dibandingkan perlakuan olah tanah penuh.Namun hasil penelitian ini ternyata tidak berbeda. Penyebab utamanya adalah rendahnya curah hujan selama penelitian dan terjadinya hujan juga tidak terus menerus, sehingga setiap kali terjadi hujan, air yang dapat masuk kedalam tanah tetap banyak. Akibatnya aliran permukaan yang terjadi sangat sedikit/ kecil.

Aliran permukaan sangat dipengaruhi oleh kemiringan dan panjang lereng, karena pada kemiringan yang curam, air bergeak secara vertikal dan juga secara horizontal, sedangkan pada kemiringan yang agak datar pergerakan air didominasi oleh pergerakan secara vertikal yang memungkinkan air lebih banyak meresap kedalam tanah. Semakin curam lereng maka semakin besar pula nilai aliran permukaannya dan sebaliknya semakin datar suatu lereng maka semakin kecil nilai aliran permukaannya. Hasil pengamatan Ispriyanto dkk (2001) pada penelitiannya mengenai Aliran Permukaan dan Erosi di Areal Tumpangsari Tanaman Pinus merkusii menunjukkan hasil yang tidak jauh berbeda yaitu pada kondisi kemiringan diatas $40 \%$ menghasilkan aliran permukaan sebesar $1,933 \mathrm{~mm}$ sedangkan untuk kemiringan dibawah 10\% menghasilkan aliran permukaan sebesar $0,260 \mathrm{~mm}$. Hal ini memperlihatkan bahwa kelerengan suatu lahan dapat memperbesar aliran permukaan.

Sifat topografi lain yang juga mempengaruhi besarnya nilai aliran permukaan adalah panjang lereng. Bermanakusuma (1978) mengatakan bahwa semakin panjang dan curam suatu signifikan terhadap tanah. Erosi sangat terkait dengan aliran permukaan, karena aliran permukaan yang terjadi rendah maka erosi juga rendah.Hasil penelitian ini sejalan dan didukung oleh pernyataan Utomo (2012) yang menyatakan bahwa pengolahan tanah membutuhkan waktu yang lama untuk berpengaruh terhadap erosi yang terjadi. Hasil penelitian ini juga didukung oleh hasil penelitian sebelumnya yang menyatakan bahwa pengolahan lahan tidak nyata

Tabel 2. Pengaruh sistem olah tanah dan herbisida terhadap aliran permukaan

\begin{tabular}{|c|c|}
\hline Perlakuan & Aliran Permukaan (mm) \\
\hline $\mathrm{F}$ & $19,01 \quad \mathrm{a}$ \\
\hline M & 16,56 a \\
\hline $\mathrm{H} 0$ & 14,58 a \\
\hline $\mathrm{H} 1$ & 20,99 a \\
\hline Nilai BNT (5\%) & 11,74 \\
\hline
\end{tabular}

Keterangan : $\mathrm{F}=$ olah tanah penuh, $\mathrm{M}=$ olah tanah minimum, $\mathrm{H} 0=$ tanpa herbisida, $\mathrm{H} 1=$ pemberian herbisida.

Nilai tengah pada tabel yang diikuti oleh huruf yang sama tidak berbeda nyata berdasarkan Uji BNT taraf $5 \%$. 
Tabel 3. Pengaruh sistem olah tanah dan herbisida terhadap erosi

\begin{tabular}{|c|c|c|}
\hline Perlakuan & \multicolumn{2}{|c|}{ Erosi (kg/ha) } \\
\hline $\mathrm{F}$ & 655,99 & $(21,80 \quad a)$ \\
\hline M & 532,88 & $(18,39$ a) \\
\hline H0 & 349,33 & $(17,00 \quad a)$ \\
\hline $\mathrm{H} 1$ & 839,49 & $(23,20 \quad a)$ \\
\hline Nilai BNT (5\%) & 1142,4 & $(19,62)$ \\
\hline
\end{tabular}

Keterangan : $\mathrm{F}$ = olah tanah penuh, $\mathrm{M}$ = olah tanah minimum, $\mathrm{H} 0$ = tanpa herbisida, $\mathrm{H} 1$ = pemberian herbisida. Nilai tengah pada tabel yang diikuti oleh huruf yang sama tidak berbeda nyata berdasarkan Uji BNT taraf 5\%. Nilai didalam kurung merupakan hasil transformasi $\sqrt{\mathrm{x}}$.

mempengaruhi erosi yang terjadi (Banuwa, dkk., 2014). Hasil penelitian ini juga sejalan dan didukung oleh penelitian Dariah, dkk. (2003) yang menyatakan bahwa penerapan teknik konservasi pada usaha tani kopi yang berumur 3 bulan di Dusun Tepus dan Laksana tidak nyata mengurangi erosi yang terjadi.

Dariah, dkk. (2003) mengemukakan bahwa air hujan yang jatuh di atas permukaan tanah dan menjadi air limpasan permukaan merupakan penyebab utama terjadinya erosi. Hujan dengan curah hujan dan intensitas yang tinggi, misalnya $67 \mathrm{~mm}$ dalam waktu singkat ( kurang dari satu jam), lebih berpotensi menyebabkan erosi dibandingkan hujan dengan curah hujan yang sama namun dalam waktu yang lebih lama (lebih dari satu jam). Intensitas curah hujan menentukan aliran permukaan yang mampu menimbulkan erosi.

Pemberian herbisida juga tidak nyata mempengaruhi erosi yang terjadi (Tabel 3). Perlakuan dengan pemberian herbisida dan tanpa pemberian herbisida menghasilkan hasil analisis ragam yang tidak berbeda. Hasil penelitian ini didukung dan sejalan dengan penelitian Banuwa, dkk. (2014), yang menyatakan bahwa herbisida tidak nyata mempengaruhi erosi yang terjadi. Hal ini terjadi karena gulma yang mati dengan pemberian herbisida, tidak mampu menekan laju aliran permukaan yang membawa erosi.

\section{Pengaruh Sistem Olah Tanah dan Herbisida terhadap Tinggi Tanaman}

Pengamatan pertumbuhan hanya dilakukan pada pengamatan tinggi tanaman jagung. Berdasarkan penelitian ini diperoleh pada perlakuan herbisida berbeda nyata sedangkan pada olah tanah tidak berbeda nyata dan Interkasi antara sistem olah tanah dan pemberian herbisida tidak nyata mempengaruhi tinggi tanaman, hasil tersebut dapat dilihat pada (Tabel 4), yang menunjukkan tanaman tertinggi pada perlakuan pemberian herbisida sebesar 191,55 cm berbeda nyata dibandingkan perlakuan tanpa pemberian herbisida yaitu sebesar $141,27 \mathrm{~cm}$. Sedangkan pada perlakuan olah tanah masing-masing tinggi tanaman tidak berbeda nyata yaitu M sebesar 161,02 cm dan F sebesar 171,8 cm. Berdasarkan hasil penelitian tersebut sejalan dengan Jamila (2007) yang menyatakan bahwa pengolahan tanah tidak nyata mempengaruhi tinggi tanaman kedelai. Dan diperkuat dengan penelitian Rayyandini (2016) menyatakan bahwa sistem olah tanah tidak mempengaruhi diameter batang dan tinggi tanaman singkong, namun pemberian herbisida nyata mempengaruhi diameter batang dan tinggi tanaman singkong.

Hal tersebut karena pada perlakuan pemberian herbisida, mengakibatkan gulma yang terdapat pada

Tabel 4. Pengaruh sistem olah tanah dan herbisida terhadap tinggi tanaman

\begin{tabular}{cc}
\hline Perlakuan & Tinggi Tanaman $(\mathrm{cm})$ \\
\hline $\mathrm{F}$ & 171,80 a \\
M & 161,02 a \\
\hline H0 & 141,27 a \\
H1 & 191,55 b \\
\hline Nilai BNT $(5 \%)$ & 40,36 \\
\hline
\end{tabular}

Keterangan : $\mathrm{F}=$ olah tanah penuh, $\mathrm{M}=$ olah tanah minimum, $\mathrm{H} 0=$ tanpa herbisida, $\mathrm{H} 1=$ pemberian herbisida. Nilai tengah pada tabel yang diikuti oleh huruf yang sama tidak berbeda nyata berdasarkan Uji BNT taraf 5\%. 
Tabel 5. Pengaruh sistem olah tanah dan herbisida terhadap bobot basah gulma

\begin{tabular}{cc}
\hline Perlakuan & Bobot Basah Gulma (ton/ha) \\
\hline F & 9,30 a \\
M & 9,46 a \\
\hline H0 & 11,96 b \\
H1 & 6,80 a \\
\hline BNT $(5 \%)$ & 5,01 \\
\hline
\end{tabular}

Keterangan : $\mathrm{F}=$ olah tanah penuh, $\mathrm{M}=$ olah tanah minimum, $\mathrm{H} 0=$ tanpa herbisida, $\mathrm{H} 1$ = pemberian herbisida. Nilai tengah pada tabel yang diikuti oleh huruf yang sama tidak berbeda nyata berdasarkan Uji BNT taraf $5 \%$.

lahan berkurang, sehingga dapat mengurangi perebutan unsur hara, air dan cahaya antara tanaman jagung dengan gulma. Sehingga pertumbuhan tinggi tanaman pada lahan penelitian perlakuan pemberian herbisida pertumbuhannya lebih baik dari pada perlakuan tanpa pemberian herbisida. Penambahan herbisida dapat mengendalikan gulma dan meningkatkan pertumbuhan pada lahan penelitian (Faqihhudin, 2014). Gulma yang mati yang disebabkan penyemprotan herbisida secara tidak langsung dapat menambahkan kadungan akan unsur hara dan bahan organik, sehingga pertumbuhan tanaman meningkat.

\section{Pengaruh Sistem Olah Tanah dan Herbisida terhadap Bobot Basah Gulma dan BobotBrangkasanTanaman Jagung}

Table 5 menunjukkan bahwa perlakuan tanpa pemberian herbisida nyata lebih tinggi menghasilkan bobot basah gulma dibandingkan pemberian herbisida. Sedangkan pada perlakuan sistem olah tanah dan interaksi antara sistem olah tanah dengan perlakuan herbisida tidak nyata berpengaruh terhadap bobot basah gulma.Pada (Tabel 5) menunjukan bahwa bobot basah gulma tertinggi terdapat pada perlakuan tanpa herbisida sebesar 11,96 ton/ha, sedangkan pada perlakuan pemberian herbisida terdapat 6,80 ton/ha gulma. Perlakuan pemberian herbisida memperoleh bobot berangkasan tanaman paling tinggi yaitu 3,74 ton/ha.
Sedangkan perlakuan aplikasitanpa herbisida memperoleh brangkasan tanaman paling rendah yaitu sebesar 2,69 ton/ha (Tabel 6)

Tabel 6 menujukkan bahwa perlakuan sistem olah tanah tidak nyata berpengaruh terhadap bobot basah brangkasan tanaman jagung, pemberian herbisida nyata lebih tinggi menghasilkan bobot basah brangkasan tanaman jagung, sedangkan interaksi antara sistem olah tanah dengan herbisida tidak nyata mempengaruhi bobot basah brangkasan. Pada perlakuan tanpa herbisida gulma yang tumbuh dilakukan pengkoretan sehingga dapat membrantas gulma hingga akarnya, dengan demikian dapat menekan populasi gulma yang menjadi pesaing tanaman budidaya sehingga bobot brangkasan pada lahan perlakuan tanpa herbisida lebih tinggi dari pada perlakuan lainnya.

\section{Pengaruh Sistem Olah Tanah dan Herbisida terhadap Produksi Tanaman Jagung}

Table 7 menunjukkan bahwa perlakuan pemberian herbisida nyata menghasilkan produksi tanaman jagung lebih tinggi dari pada tanpa pemberian herbisida. Sedangkan pada perlakuan sistem olah tanah dan interaksi antara sistem olah tanah dan herbisida tidak nyata berpengaruh pada produksi tanaman jagung. Setiapperlakuan memiliki produksi tanaman jagung sebesar 6,16 ton/ha pada perlakuan olah tanah penuh, 5,38 ton/ha pada perlakuan olah tanah minimum, 4,72

Tabel 6. Pengaruh sistem olah tanah dan herbisida terhadap bobot basah brangkasan

\begin{tabular}{ccc}
\hline Perlakuan & Bobot Basah Brangkasan (ton/ha) \\
\hline F & 11,86 & $(3,39$ a) \\
M & 9,91 & $(3,04$ a) \\
\hline H0 & 7,44 & $(2,69$ a) \\
H1 & 14,34 & $(3,74$ b) \\
\hline Nilai BNT (5\%) & 3,13 & $(0,41)$ \\
\hline
\end{tabular}

Keterangan : $\mathrm{F}=$ olah tanah penuh, $\mathrm{M}=$ olah tanah minimum, $\mathrm{H} 0=$ tanpa herbisida, $\mathrm{H} 1=$ pemberian herbisida. Nilai tengah pada tabel yang diikuti oleh huruf yang sama tidak berbeda nyata berdasarkan Uji BNT taraf 5\%. Nilai didalam kurung merupakan nilai transformasi $\sqrt{ } \mathrm{x}$. 
Tabel 7. Pengaruh sistem olah tanah dan herbisida terhadap produksi jagung

\begin{tabular}{cc}
\hline Perlakuan & Produksi Jagung (ton/ha) \\
\hline $\mathrm{F}$ & $6,16 \mathrm{a}$ \\
$\mathrm{M}$ & $5,38 \mathrm{a}$ \\
\hline $\mathrm{H} 0$ & $4,72 \mathrm{a}$ \\
$\mathrm{H} 1$ & $6,82 \mathrm{~b}$ \\
\hline Nilai BNT $(5 \%)$ & 1,87 \\
\hline
\end{tabular}

Keterangan : $\mathrm{F}=$ olah tanah penuh, $\mathrm{M}=$ olah tanah minimum, $\mathrm{H} 0=$ tanpa herbisida, $\mathrm{H} 1=$ pemberian herbisida. Nilai tengah pada tabel yang diikuti oleh huruf yang sama tidak berbeda nyata berdasarkan Uji BNT taraf 5\%.

ton/ha pada perlakuan tanpa herbisida dan 6,82 ton/ha pada perlakuan pemberian herbisida. Produksi yang didapat ini cukup baik dalam jumlah produksi rata-rata tanaman jagung per hektar. Menurut Badan Pusat Stastistik Propinsi Lampung (2013), produktivitas jagung dewasa ini di propinsi lampung sebesar 5 ton/ha. Berdasarkan data tersebut produksi tanaman jagung masih masuk dalam produktivitas jagung di Lampung, dengan demikian aliran permukaan dan erosi yang terjadi selama masa penelitian tanaman jagung tidak mempengaruhi pertumbuhan tanaman jagung sehingga produksinya tetap tinggi.

Mukhlis (2004, dalam Burhanuddin, 2015) melaporkan bahwa penyiapan lahan dengan herbisida terbukti mampu mengurangi secara nyata hilangnya top soil akibat erosi sekaligus menciptakan iklim mikro yang kondusif bagi pertumbuhan tanaman dan meningkatkan kesuburan tanah. Selain itu hasil penelitian Adnan dkk., (2012) menunjukkan bahwa penggunaan herbisida dapat mempengaruhi sifat kimia tanah, sehingga terjadi peningkatan konsentrasi K-dd dalam tanah setelah penggunaan hebisida. Peningkatan K-dd tanah tidak terlepas dari sumbangan sejumlah unsur hara khususnya kalium yang dihasilkan dari gulma yang mati akibat penggunaan herbisida yang mengalami pelapukan dan mineralisasi menjadi unsur hara yang tersedia untuk diserap tanaman. Dengan demikian bahan organik dalam tanah meningkat sehungga dapat memperbaiki sifat fisika tanah yaitu dapat memperbaiki aeraasi tanah dan menggemburkan tanah.Aplikasi herbisida pada penelitian ini berpengaruh nyata terhadap produksi tanaman jagung (Tabel 7). Pemberian herbisida dapat meningkatkan produksi tanaman jagung jika dibandingkan dengan tanpa pemberian herbisida. Dengan pemberian herbisida dapat memperbaiki sifat fisika tanah seperti tekstur tanah menjadi lebih gembur, dapat menurunkan laju evaporasi tanah sehingga tanah tetap lembab, memperbaiki ruang pori tanah yang menjadi tempat respirasi tanah. Menurut Faqihhudin (2014), penggunaan herbisidaglifosatdengan berbagai dosisberpengaruh pada pertumbuhan dan hasil tanaman jagung. Hasil parameterpertumbuhan tertinggi terdapatpadaperlakuan herbisidaglifosatdosis $41 /$ ha. Polayang sama teramati pada peubah hasil jagung yang didukung oleh pernyataan Triyono (2011) yang menyatakan bahwa penggunaan glifosat dengan dosis 4 1/ha sudah mampu memberi kondisi lingkungan yang memungkinkan tanaman jagung memberikan komponen hasil tinggi jauh dibandingkan dengan yang tanpa diberi glifosat. Peningkatan dosis glifosat yang diaplikasikan akan semakin menekan populasi gulma sehingga produksi jagung meningkat.

\section{KESIMPULAN DAN SARAN}

\section{Kesimpulan}

Dari penelitian yang telah dilakukan, maka dapat ditarik kesimpulan sebagai berikut:

1. Aliran permukaan, erosi, tinggi tanaman, bobot basah gulma, bobot brangkasan tanaman dan produksi tanaman jagung pada olah tanah minimum tidak berbeda dibandingkan olah tanah penuh.

2. Aliran permukaan dan erosi pada perlakuan pemberian herbisida tidak berbeda dibandingkan tanpa pemberian herbisida, tetapi pada tinggi tanaman, bobot gulma, bobot brangkasan dan produksi tanaman jagung berbeda.

3. Tidak ada interaksi yang terjadi antara perlakuan sistem olah tanah dan herbisida terhadap aliran permukan dan erosi, tinggi tanaman, bobot basah gulma, bobot brangkasan tanaman dan produksi tanaman jagung.

\section{Saran}

Berdasarkan hasil penelitian dan pembahasan, disarankan untuk melakukan penelitian lanjutan yaitu dengan menambah perlakuan dosis pemberian herbisida dan pengaruh curah hujan agar dapat mengetahui dampak terhadap aliran permukaan dan erosi. 


\section{DAFTAR PUSTAKA}

Arsyad, S. 2010. Konservasi Tanah dan Air. Edisi Kedua. IPB Press. Bogor. 472 hlm.

Badan Pusat Statistik Propinsi Lampung.2013. Luas Panen dan Produksi dan Produktivitas Tanaman Jagung. Lampung.

Banuwa, I.S. 2013. Erosi. Kencana Prenada Media Group. Jakarta. 205 hlm.

Banuwa, I.S., Andhi, U. Hasanudin, and K. Fujie. 2014. Erosi and Nutrient Enrichment under Different Tillage and Weed Control Systems.Procedings 9th IWA International Sypomsium on Waste Management Problems in Agro-Industries. (2) : $120-125$.

Bermanakusuma, R. 1978. Erosi, Penyebab dan Pengendaliannya. Fakultas

Pertanian. Universitas Padjajaran. Bandung.

Dariah, A., F. Agus, S. Arsyad, Sudarsono, dan Maswar. 2003. Erosi dan Aliran Permukan pada Lahan Pertanian Berbasis Tanaman Kopi di Sumberjaya. Lampung Barat. Jurnal Agrivisa, 26 (1): 52-60.

Faqihhudin, M.Danang. 2014. Penggunaan Herbisida IPA-Glifosat terhadap Pertumbuhan, Hasil dan Residu pada Jagung. Jurnal Ilmu Pertanian. (17):1-8.

Gajri, P.R., V.K. Arora, and S.S. Prihar.2002. Tillage for Suistainable Cropping. The Haworth Press. New York.

Gill, W.R., and G.E. Vanden Berg. 1967. Soil Dynamics in Tillage and Traction. USDA Agric. Handb. N. 316. U.S. Government Printing Office, Washington, DC.
Jamila., Kaharuddin. 2007. EfektivitasMulsa dan SistemOlah Tanah terhadap Produktivitas TanahDangkaldan BerbatuuntukProduksi Kedelai. Jurnal Agrisistem. 3 (2) : 65 - 75

Ispriyanto R, NM Arifjaya dan Hendrayanto. 2001. Aliran Permukaan dan Erosi di Areal Tumpangsari Pinus merkusii Jungh. Et de Vriese. Jurnal Manajemen Hutan Tropika. 7 (1) : 37-47

Kartasapoetra, G., A.G. Kartasapoetra, M.M. Sutedjo. 1991. Teknologi Konservasi Tanah dan Air Edisi Kedua. PT Rineka Cipta. Jakarta. 212 hlm.

Rayyandini, K. 2016. Pengaruh Sistem Olah Tanah dan Pemberian Herbisida Terhadap Aliran Permukaan dan Erosi pada Fase Generatif Pertanaman Singkong (Manihot utilissima) Musim Tanam Ke-2. (Skripsi). Jurusan Agroteknologi. Fakultas Pertanian. Universitas Lampung. Bandar Lampung.

.Roesmarkam, A. dan N. W. Yuwono. 2002. Ilmu Kesuburan Tanah. Penerbit Kanisius. Yogyakarta

Sembodo, D.R.J. 2010. Gulma dan Pengelolaannya. Graha Ilmu. Yogyakarta. $168 \mathrm{hlm}$.

Suwarjo. 1981. Peranan Sisa-sisa Tanaman dalam Konservasi Tanah dan Air pada Usahatani Tanaman Semusim. Disertasi FPS IPB. Bogor.

Triyono, K. 2011. Pengaruh dosis glifosat dan jarak tanam terhadap pertumbuhan gulma dan hasil jagung (Zea mays L.). J. Inov. Pert 9 (2) :17-24

Utomo, Wani Hadi. 1995. Erosi dan Konservasi Tanah. Penerbit IKIP. Malang. 